\title{
Large aerosol optical depths observed at an urban location in southern India associated with rain-deficit summer monsoon season
}

\author{
V. Vinoj ${ }^{1}$, S. K. Satheesh ${ }^{1}$, S. Suresh Babu ${ }^{2}$, and K. Krishna Moorthy ${ }^{2}$ \\ ${ }^{1}$ Centre for Atmospheric and Oceanic Sciences Indian Institute of Science, Bangalore-560 012, India \\ ${ }^{2}$ Space Physics Laboratory Vikram Sarabhai Space Centre, Trivandrum-695 022, India
}

Received: 5 February 2004 - Revised: 3 June 2004 - Accepted: 9 June 2004 - Published: 7 September 2004

\begin{abstract}
Aerosol spectral optical depth (AOD) measurements were made covering three years (2001, 2002 and 2003) at an urban continental location, Bangalore $\left(13^{\circ} \mathrm{N}, 77.6^{\circ} \mathrm{E}\right)$ in India. These ground-based observations have shown that AODs reach a maximum during April $(\sim 0.5$ at $500 \mathrm{~nm})$ and minimum during the November to January period $(\sim 0.2)$. The Angstrom wavelength exponent $(\alpha)$ was $\sim 1.1$ during the dry season (December to April), which, in conjunction with the high optical depth indicates significant anthropogenic influence. Seasonal variations in AODs appear to have an association with monsoon rainfall. Large AODs $(\alpha \sim 1.4)$ were observed during the rain-deficit summer monsoon season (SMS) of 2002, which persisted for more than six months. Enhancement in AODs during SMS 2002 was $\sim 0.15$ (at $500 \mathrm{~nm}$ ), compared to 2001 and 2003.
\end{abstract}

Key words. Atmospheric composition and structure (Aerosols and particles; pollution-urban arid regional) - Meteorology and atmospheric dynamics (radiative processes)

\section{Introduction}

Aerosols have the potential to alter the Earth's energy balance and hence the climate (Charlson et al., 1991, 1992; Andreae, 1995, Kaufman et al., 1998; Satheesh and Ramanathan, 2000). Since the sources of anthropogenic aerosols are located primarily over land, the radiative forcing of aerosols is larger over land (Charlson et al., 1991, 1992; Kaufman et al., 1998; Subbaraya et al., 2000; Moorthy et al., 2001; Babu et al., 2002). Moreover, land responds more quickly than ocean to any change in radiation flux due to its low heat capacity compared to the ocean (Heintzenberg et al., 1997; Satheesh, 2002). The radiative impacts due to absorbing aerosols (such as soot) are more significant over land (due to its higher surface reflectance) than over oceans

Correspondence to: S. K. Satheesh

(satheesh@ caos.iisc.ernet.in)
(Heintzenberg et al., 1997; Satheesh et al., 1999; Kaufman et al., 2001; Satheesh, 2002).

In this paper, we examine the seasonal variations of the spectral aerosol optical depth (AOD) for three years (2001, 2002 and 2003) that were obtained at an urban continental location, Bangalore $\left(13^{\circ} \mathrm{N}, 77.6^{\circ} \mathrm{E}\right.$; $\left.960 \mathrm{~m} \mathrm{MSL}\right)$ in India as part of Indian Space Research Organization's Geosphere Biosphere Programme (GBP) (Moorthy et al., 1999; Babu et al., 2002). Impact of the change in meteorological conditions and a large deficit of rainfall during the summer monsoon season of 2002 on the spectral AODs are presented.

\section{Results}

\subsection{Aerosol spectral optical depths}

AOD measurements were made using a Microtops-II Sun photometer at approximately half-hour intervals whenever the sky was clear or the Sun was away from the clouds. Microtops-II is a 5-channel hand-held Sun photometer used to measure the instantaneous aerosol optical depth from individual measurements of direct solar flux, using a set of internal calibration constants (Morys et al., 2001; Ichoku et al., 2002). A Global Positioning System (GPS) receiver attached to the photometer provides information on the location, altitude and pressure. The wavelengths are centered about 340 , $380,500,675$ and $870 \mathrm{~nm}$, with a full width half-maximum bandwidth of 2 to $10 \mathrm{~nm}$ and a field of view of $2.5^{\circ}$.

Various types of errors occurring in Sun photometry have been documented (Shaw, 1976; Box and Deepak, 1979; Russell et al., 1993). According to these studies, the overall error in the aerosol optical depth can be due to a) diffuse radiation entering the optical channel, b) computation error in relative air mass (a geometrical term to account for the relative increase in optical path length as solar zenith angle increases), c) deviation of the calibration coefficient with time and d) error associated with the uncertainty in the optical depths due to Rayleigh scattering and absorption by $\mathrm{O}_{3}, \mathrm{NO}_{2}$ and water 


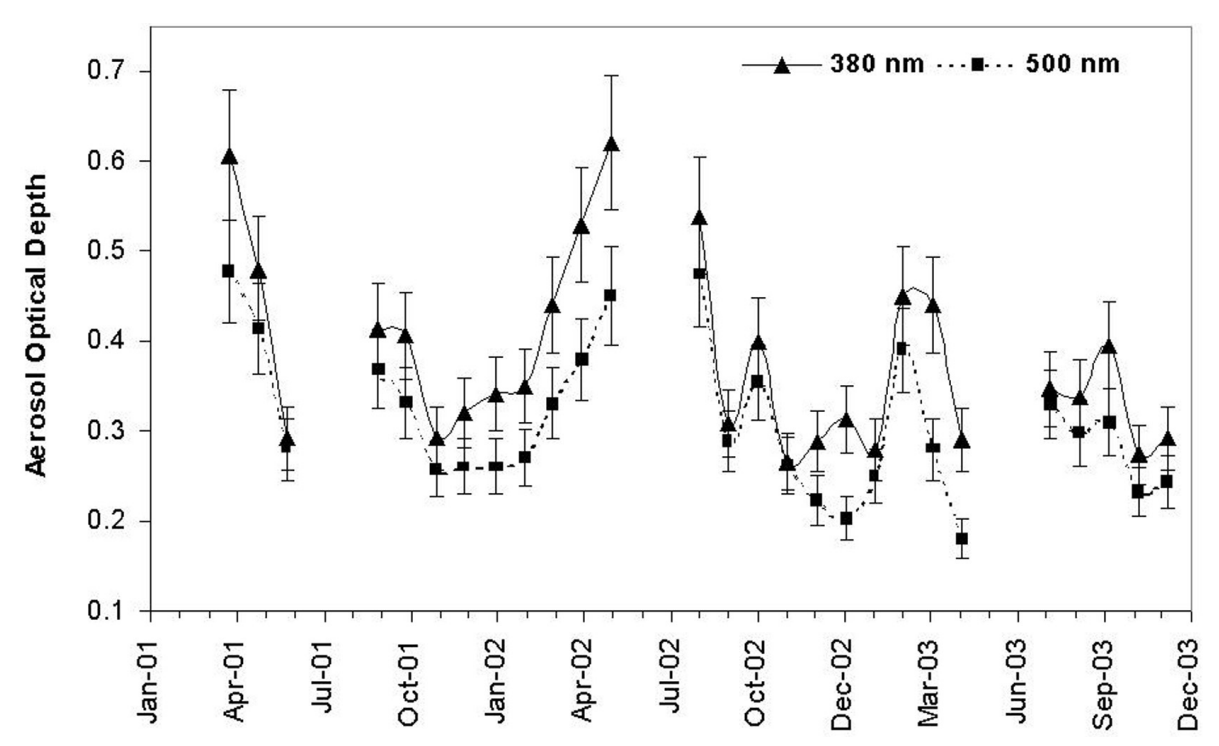

Fig. 1. Temporal variation of aerosol optical depth at two representative wavelengths $(380 \mathrm{~nm}$ and $500 \mathrm{~nm})$.

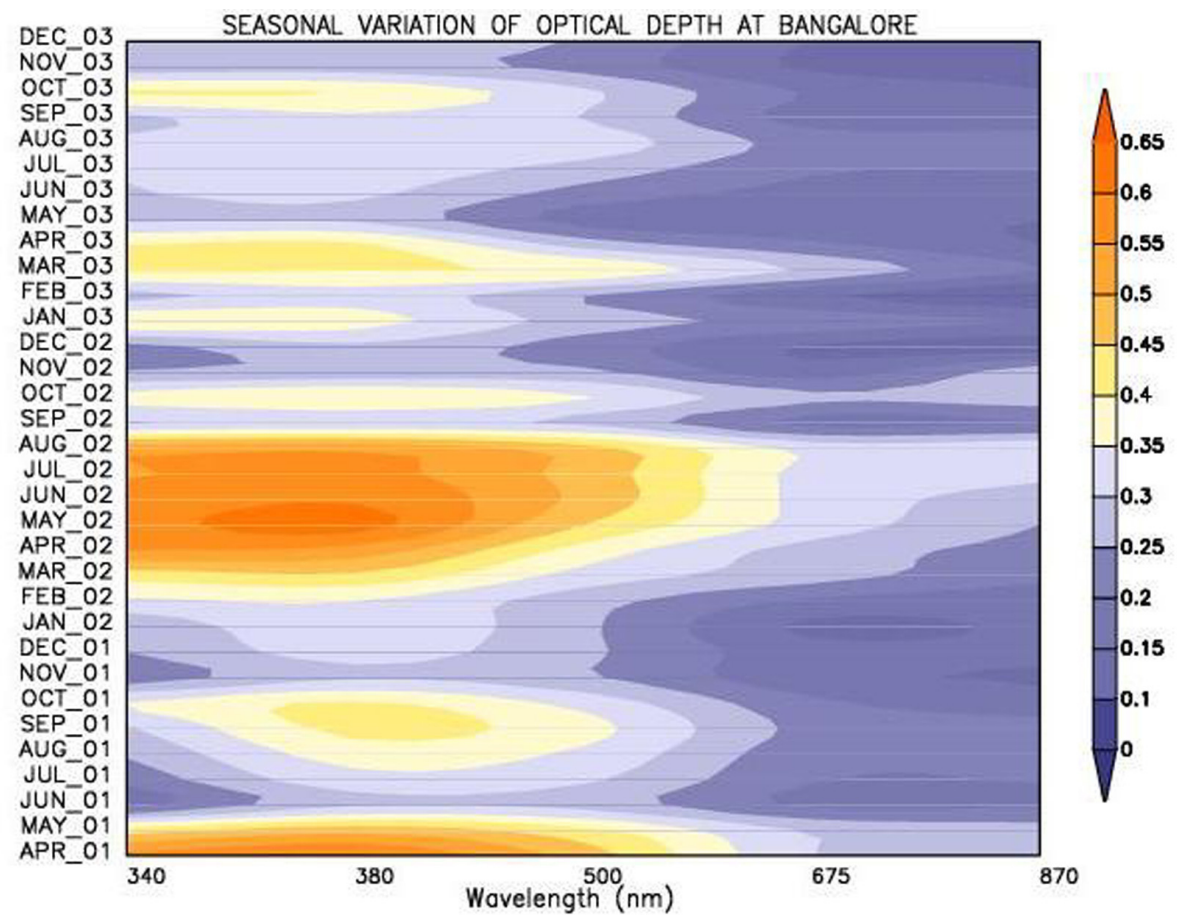

Fig. 2. Temporal and spectral variation of aerosol optical depths.

vapour. It has been shown (e.g. Box and Deepak, 1979) that for a moderately turbid atmosphere the diffuse radiation entering into the optics would be less than $3 \%$ of the direct radiation for a field of view of $2.5^{\circ}$ (in our case). The combined error in the estimated aerosol optical depth due to all the above mentioned errors is in the range of 0.009 to 0.011 at different wavelengths (which is $2 \%$ to $10 \%$ of the aerosol optical depth).
Typically during a clear sky day, the number of observations were in the range of 15 to 20 . During the dry season (December to April) observations were possible on almost all days, but during the rest of the year the number of days of observations were in the range of 5 to 10 , restricted by the sky conditions. Monthly variations of AODs at two representative wavelengths $(380 \mathrm{~nm}$ and $500 \mathrm{~nm})$ are shown in Fig. 1, while the average spectral-temporal variations are shown in 
Fig. 2 as a contour plot. Vertical bars in Fig. 1 represent standard deviations of the monthly mean. It may be noted that during June and July we do not have AODs due to cloudy skies (Fig. 1). However, AOD (at $550 \mathrm{~nm}$ ) from the MODIS sensor (on board the TERRA satellite) was available for a few days in June and July. It may be noted that the groundbased observations $(500 \mathrm{~nm})$ and MODIS $(550 \mathrm{~nm})$ observations were made at two different wavelengths. The root mean square (rms) difference between ground-based observations and MODIS observations after correcting for the wavelength dependence is $\sim 0.06$. In Fig. 2, for June/July (during which ground based measurements were not available), we have used MODIS AODs (level 3) after correcting for the wavelength dependence and mean difference with ground-based measurements.

There is a clear, seasonal variation in the aerosol optical depth at Bangalore and the variations are more pronounced at the shorter wavelengths (Fig. 2). The AODs show a maximum during April $(\sim 0.5$ at $500 \mathrm{~nm})$ and minimum during the November to January period $(\sim 0.2)$. At shorter wavelengths $(\lambda<0.6 \mu \mathrm{m}$ ), AODs were always greater than 0.25 (for the entire data period) when compared to the longer wavelength region $(\lambda>0.6 \mu \mathrm{m})$, where the lowest AOD was around 0.1. Steady increase in AODs from January to April, seen consistently in the data, could be attributed to the dry conditions prevailing over the station. During 2001, monsoon rainfall started in May and AODs decreased rapidly. However, during 2002 (rain-deficit year), the large values of AODs, builtup from January to April, remained at the higher levels until August; thereafter decreased abruptly. The build-up in aerosol optical depth during the dry season is generally gradual, but the decrease was rather abrupt.

The climatological values of monthly total rainfall averaged for Bangalore (averaged for Bangalore over 159 years from 1837 to 1996) (Fig. 3) shows that monsoon rainfall intensifies from May and maximum rainfall occurs during September-October months. During the December to April period rainfall is low. The absence of rainfall during the period from January to April could be responsible for the buildup in the AODs at shorter visible wavelengths (because of the absence of wet removal processes, which are most important for sub-micron aerosols) (Pruppacher and Klett, 1978). During the year 2002, overall rainfall over India was low, in general, particularly in southern India. The regional distribution of rainfall over southern India during the summer monsoon season of 2001 and 2002 is shown in Fig. 4 data obtained from the NCEP (National Centre for Environmental Prediction) database. Examining the AOD pattern in the light of Fig. 4 suggests that the dry conditions over an extended period might have influenced the aerosol loading during 2002. The spectral aerosol optical depths over Bangalore (averaged over May, June, July, August, September) for 2001, 2002 and 2003 are shown in Fig. 5. Vertical bars represent standard deviations. An enhancement in AODs (at $500 \mathrm{~nm}$ ) during 2002 is clearly discernible.

The following can be inferred from the above discussion and Figs. 1 and 2: a) aerosol optical depths start building up

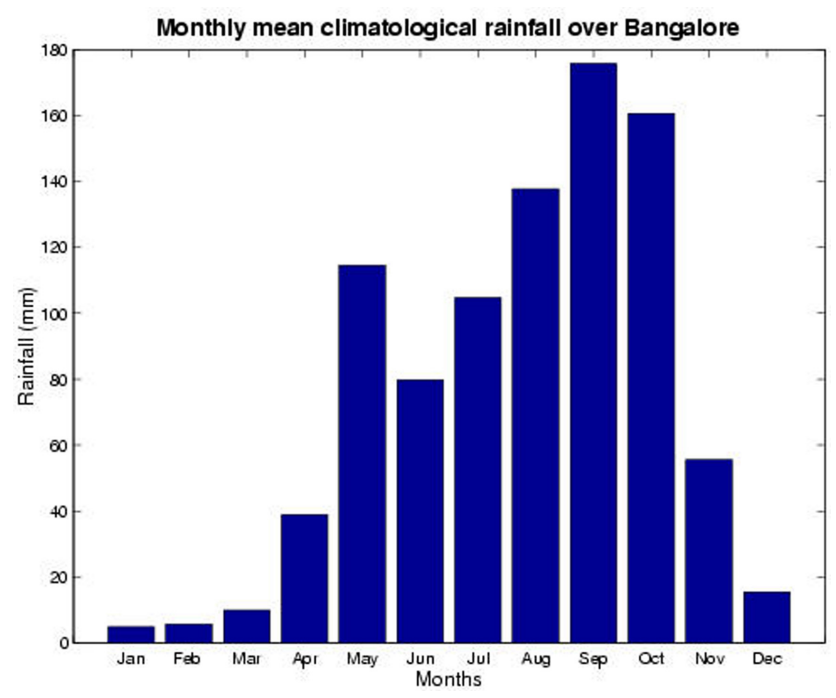

Fig. 3. Climatological rainfall at Bangalore.

from January and attain the maximum for the year generally just prior to the onset of monsoon rains; $b$ ) a secondary maximum occurs during the break in monsoon rainfall around August; c) the increase in AODs is gradual, whereas the decrease is abrupt (which could be due to the immediate removal of aerosols by rainfall); d) the variation of AODs with season is more prominent at the shorter wavelengths compared to longer wavelengths and e) the AOD is higher than 0.25 at shorter wavelengths during all seasons.

\subsection{Size characteristics}

A simple way of representing the spectral variation of aerosol optical depth $\left(\tau_{p \lambda}\right)$ is by using Angstrom power law given by,

$\tau_{p \lambda}=\beta \lambda^{-\alpha}$,

where $\alpha$ is the Angstrom wavelength exponent indicating relative dominance of larger aerosol over smaller ones, $\beta$ (i.e. $\tau_{p \lambda}$ at $\left.1 \mu \mathrm{m}\right)$ is the turbidity parameter indicating the aerosol loading and $\lambda$ is the wavelength in $\mu \mathrm{m}$ (Angstrom, 1964; Shaw et al., 1973). Lower values of $\alpha$ indicate larger abundance of super micron aerosols (Satheesh and Moorthy, 1997). As the smaller particles over continental locations are primarily produced by anthropogenic activities, the value of $\alpha$ can be considered as a measure of anthropogenic influence (Moorthy et al., 1999, 2001; Moorthy and Satheesh, 2000).

Our observations have shown that $\alpha$ normally decreases drastically from $\sim 1.0$ during April 2001 to $\sim 0.15$ during June 2001. Thereafter, $\alpha$ increases and reaches a secondary maximum $(\sim 0.9)$ during August/September. However, in 2002 , the increase in $\alpha$ from January $(\sim 0.5)$ continued up to August $2002(\sim 1.1)$, thereafter reaching a minimum value $(\sim 0.1)$ in November 2002. Thus, it can be inferred that there is a large anthropogenic influence during the dry season prior to monsoon rainfall (especially January to May) 


\section{RAINFALL OVER SOUTH INDIA}

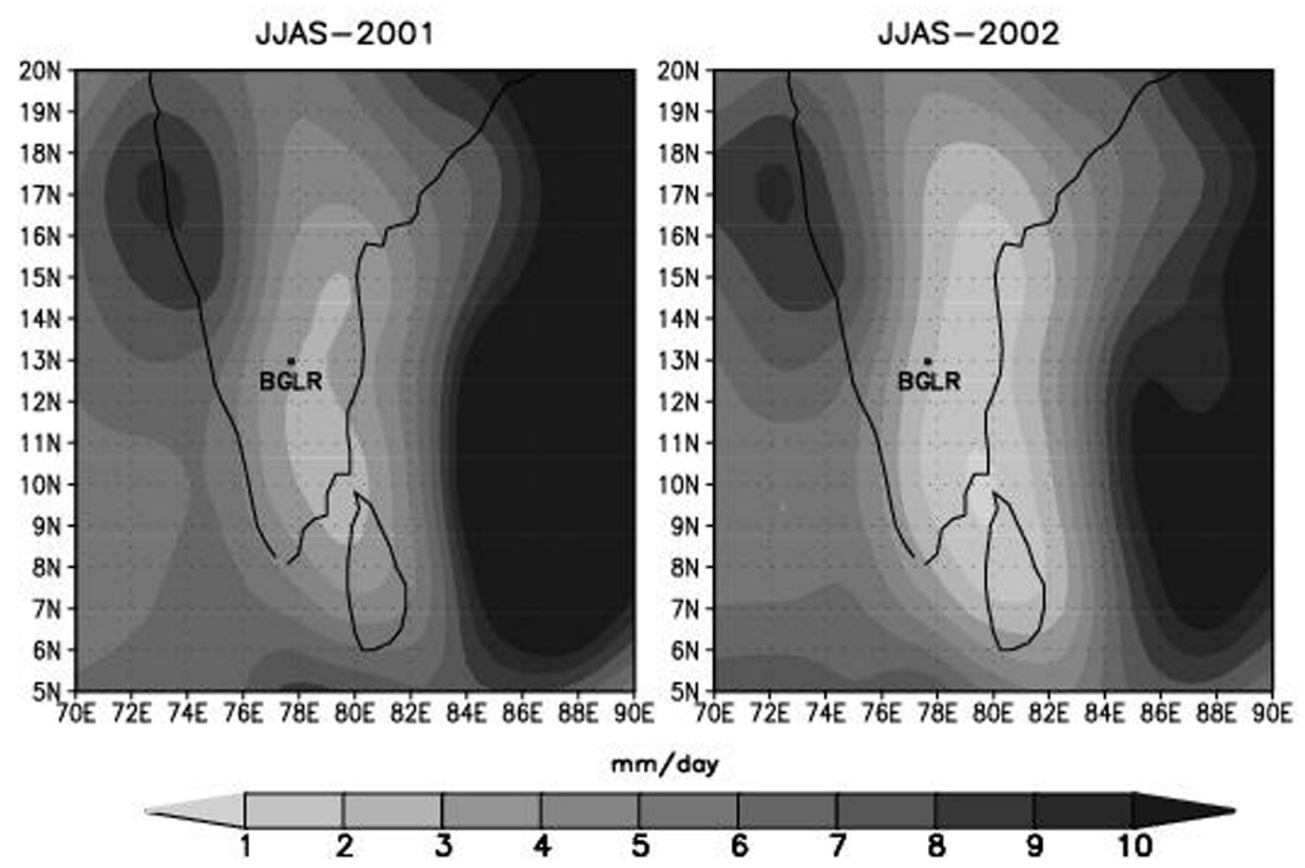

Fig. 4. Regional distribution of rainfall at Bangalore during 2001 and 2002.

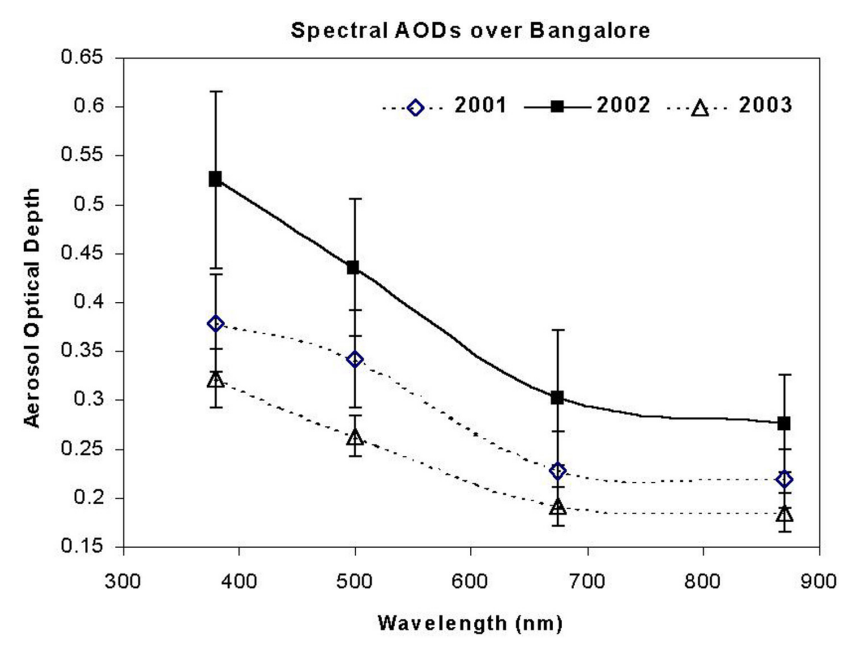

Fig. 5. Spectral optical depths at Bangalore (May, June, July, August, September mean) for 2001, 2002 and 2003.

at Bangalore. The temporal extent of large AODs depends on the onset of monsoon, usually in June but occasionally it extends up to the month of August, as was the case during 2002.

In monsoon season, rainfall is widespread and consequently, the entire region is depleted of aerosol loading. This is in contrast to isolated rains where the wash out is only local and will be replenished soon by the transport of aerosols (mostly sub-micron in size and are long-lived) from nearby regions which are not affected by rain. However, during monsoon, aerosols over a very large area are af- fected and hence AOD remains low for three to four months. Sub-micron aerosols (which are several orders of magnitude larger in number compared to super-micron aerosols) are mostly affected by rain (and hence the AODs at shorter visible wavelengths) (Flossman et al., 1985). Thus, if there is a local rainfall deficiency, there will be a large increase in the AODs at shorter visible wavelengths. The super-micron aerosols (which influence the AODs at near IR wavelengths) are more localized and short-lived.

\section{Conclusions}

The major conclusions from our study are the following:

1. AODs over Bangalore show maximum during April $(\sim 0.5$ at $500 \mathrm{~nm})$ and minimum during November to January period $(\sim 0.2)$.

2. The Angstrom wavelength exponent $(\alpha)$ was $\sim 1.1$ during the dry season, which, in conjunction with the high optical depths, indicates significant anthropogenic influence.

3. The onset of monsoon rainfall causes a drastic decrease in AODs due to wet removal, whereas the buildup in AODs during dry season is gradual.

4. Large AODs (with $\alpha \sim 1.4$ ) were observed during the rain-deficit summer monsoon season of 2002, which persisted for more than six months. 
5. Enhancement in AODs during SMS 2002 was $~ 0.15$ (at $500 \mathrm{~nm}$ ) compared to 2001 and 2003.

6. Seasonal variations in AODs appear to have an association with monsoon rainfall.

Acknowledgements. This research work forms part of aerosol characterisation programme of ISRO-Geosphere Biosphere Programme (ISRO-GBP) and ISRO-RESPOND Programme. Authors thank J. Srinivasan of Centre for Atmospheric and Oceanic Sciences, Indian Institute of Science for valuable discussions and suggestions.

Topical Editor O. Boucher thanks a referee for his help in evaluating this paper.

\section{References}

Andreae, M. O.: Climatic effects of changing atmospheric aerosol levels in World survey of Climatology, vol. 16, Future Climates of the World, edited by Henderson-Sellers, A., Elsevier, New York, 341-392, 1995.

Angstrom, A.: Techniques of determining the turbidity of the atmosphere, Tellus, 13, 214, 1964

Babu, S. S., Satheesh, S. K., and Krishna Moorthy, K.: Enhanced aerosol radiative forcing due to aerosol black carbon at an urban site in India, Geophys. Res. Lett., 29, doi:10.1029/2002GL015826, 2002.

Box, M. A. and Deepak, A.: Atmospheric Corrections to Solar Radiometry, Applied Optics, 12, 1941-19, 1979.

Charlson, R. J., Langner, J., Rodhe, H., Leovy, C. B., and Warren, S. G.: Perturbation of the Northern Hemisphere Radiative balance by Backscattering from Anthropogenic Sulphate Aerosols, Tellus, 43AB, 152-163, 1991.

Charlson, R. J., Schwartz, S. E., Hales, J. M., et al.: Climate forcing by anthropogenic aerosols, Science, 255, 423-430, 1992.

Flossmann, A. I., Hall, W. D., and Pruppacher, H. R.: A theoretical study of the wet removal of atmospheric pollutants, Part I: The redistribution of aerosol particles captured through nucleation and impaction scavenging, J. Atmos. Sci., 42, 583-606, 1985.

Heintzenberg, J., Charlson, R. J., Clarke, A. D., et al.: Measurements and modeling of aerosol single scattering albedo: Progress, problems and prospects, Beitr. Phys. Atmosph., 70, 249-263, 1997

Ichoku, I., Levy, R., Kaufman, Y. J., Remer, L. A., Li, R. R., Martins, V. J., Holben, B. N., Abuhassan, N., Slutsker, I., Eck, T. F., and Pietras, C.: Analysis of the performance characteristics of the five-channel Microtops II Sun photometer for measuring aerosol optical thickness and perceptible water vapour, J. Geophys. Res., 107, doi:10.1029/2001JD001302, 2002.
Kaufman, Y. J., Hobbs, P. V., Kirchhoff, V. W. J. H., et al.: Smoke, Clouds, and Radiation-Brazil (SCAR_B) experiment, J. Geophys. Res., 103, 31 783-31 808, 1998.

Kaufman, Y. J., Tanre, D., Dubovik, O., et al.: Satellite and groundbased radiometers reveal much lower dust absorption of sunlight than used in climate models, Geophys. Res. Lett., 28, 14791483, 2001.

Moorthy, K. K., Niranjan, K., Narasimhamurthy, B., et al.: Aerosol Climatology over India, 1 - ISRO GBP MWR network and data base, ISRO GBP SR-03-99, 1999.

Moorthy, K. K. and Satheesh, S. K.: Characteristics of aerosols over a remote island, Minicoy in the Arabian Sea: Optical properties and retrieved size characteristics, Q. J. Roy. Met. Soc., 126, 81$109,2000$.

Moorthy K. K., Saha, A., Prasad, B. S. N., et al.: Aerosol optical depths over peninsular India and adjoining oceans during the INDOEX campaigns: Spatial, temporal, and spectral characteristics, J. Geophys. Res., 106 (D22): 28 539-28 554, 2001.

Morys, M., Mims, F. M., Hagerup, S., Anderson, S. E., Baker, A., Kia, J., and Walkup, T.: Design, calibration, and performance of MICROTOPS II handheld ozone monitor and Sun photometer, J. Geophys. Res., 106, 14 573-14 582, 2001.

Pruppacher, H. R. and Klett, J. D.: Microphysics of Clouds and Precipitation, D. Reidel Publ. Co., Boston, 714, 1978.

Russell, P. B., Livingston, J. M., Dutton, E. G., Pueschel, R. F., Reagon, J. A., Defoor, T. E., Box, M. A., Allen, D., Pilewskie, P., Herman, B. M., Kinnie, S. A. and Hofmann, D. J.: Pinatubo and Pre-Pinatubo optical depth spectra: Mauna Loa measurements, comparisons, inferred particle size distribution, radiative effects and relationship to Lidar data, J. Geophys. Res., 98, 22969 22 985, 1993.

Satheesh S. K. and Krishna Moorthy, K.: Aerosol characteristics over coastal regions of the Arabian Sea, Tellus, 49B, 417-428, 1997.

Satheesh, S. K., Ramanathan, V., Jones, X. L., Lobert, J. M., Podgorny, I. A., Prospero, J. M., Holben, B. N., and Loeb, N. G.: A Model for the natural and anthropogenic aerosols for the tropical Indian ocean derived from Indian ocean Experiment data, J. Geophys. Res., 104, D22, 27, 42 127, 440, 1999.

Satheesh, S. K. and Ramanathan, V.: Large differences in the tropical aerosol forcing at the top of the atmosphere and Earth's surface, Nature, 405, 60-63, 2000

Satheesh, S. K.: Aerosol radiative forcing over land: Effect of surface and cloud reflection, Ann. Geophys., 20, 1-5, 2002.

Shaw, G. E., Regan, J. A., and Herman, B. M.: Investigations of atmospheric extinction using direct solar radiation measurements made with a multiple wavelength radiometer, J. Appl. Meteorol., 12, 374-380, 1973.

Shaw, G. E.: Error analysis of multiwavelength sun photometry, Pur. Appl. Geophys., 114, 1-14, 1976.

Subbaraya, B. H.: A. Jayaraman, K. Krishna Moorthy and M. Mohan, Atmospheric aerosol studies under ISRO's Geopshere Biosphere Programme, J. Indian Geophys. Union, 4, 77-90, 2000. 